\title{
Web Appendix to Quasi-Experimental Evidence on The Connection Between Property Taxes and Residential Capital Investment
}

\author{
Byron Lutz
}




\section{Appendix}

\subsection{Data Appendix}

\section{Municipal and School District Variables}

Total property tax payments, ptax $x_{m, t}$, contain both school and municipal property tax collections. Municipal property tax rates are set by the individual towns. School tax rates are set by the citizens of the town(s) which comprise the school district. In most cases towns and school districts have coterminous boundaries, although some towns participate in cooperative school districts composed of two or more municipalities. For cooperative districts, the school property tax payments are mapped from the school district level to the municipal level following the convention used by the New Hampshire Department of Education: Each town's school district taxes are assumed equal to the percentage of district enrollment the town accounts for times total school district taxes.

\section{The Stock of Single-Family Homes in 1996}

The stock of single-family homes in 1996 (the first year of the sample), hstock $_{m}$, is constructed as follows. The stock of single-family homes in 1990 is obtained from the 1990 Census. The 1990 stock is then increased by the number of building permits issued between 1990 and 1995 . This 1996 stock number is then adjusted as follows. The 1990 stock is grown out by the number of building permits issued between 1990 and 1999 to construct a 2000 stock measure. The difference between the 2000 constructed stock measure and the 2000 stock measured obtained from the 2000 Census is taken as the estimated error in the growth procedure. The 1996 stock measure is then adjusted using the estimated error under the assumption that the error is apportioned equally to each year between 1990 and 2000.

\section{Omitted Observations}

The observation from the municipality of Seabrook is omitted from the estimation sample. Seabrook contains a nuclear power plant. The plant was successively devalued over the course of the 1990s. As a result, Seabrook lost close to $\$ 800$ million in property value, a situation which generates uncertainty concerning the data quality of the variables pertaining to property wealth and property taxes (specifically, there appears to be longitudinal inconsistency in how the contribution of the power plant to Seabrook's tax base and tax revenue is handled). This is a unique situation unrelated to the school finance reform. Two municipalities participating in inter-state school districts (both municipalities are in cooperatives with municipalities in Vermont) are omitted from the sample. These municipalities are dropped due to longitudinal inconsistency in the data.

\section{New England Control Group Definitions}


The Southern Maine control group is defined as all Maine communities within 175 driving miles of Boston - over 99 percent of the New Hampshire sample lives within this radius. The Western Massachusetts control group is defined as all Massachusetts communities greater than 33 miles from Boston - the New Hampshire community closest to Boston is located 33 miles from the city - and west of $71.3837 \mathrm{~W}$. The Southeastern Maine control group is defined as communities east of $70.1970 \mathrm{~W}$ and within 175 miles of Boston. Central New England is defined as communities in Massachusetts south of $42.1497 \mathrm{~N}$, west of $71.3837 \mathrm{~W}$ and located 33 miles or more from Boston and communities in Rhode Island and Connecticut north of $41.8645 \mathrm{~N}$. The control group including all Connecticut, Massachusetts, Maine and Rhode Island communities between 33 and 135 miles from Boston was constructed to be as similar as possible to New Hampshire in terms of distance from Boston. The 33 mile cutoff reflects that fact that the New Hampshire town closest to Boston is 33 miles away. The 135 mile cutoff was chosen such that the mean distance in the control group exactly matches the mean distance in New Hampshire. This control group is also broadly similar to New Hampshire in terms of standard deviation and distribution.

\section{Distance from Boston}

The distance between a municipality and Boston is defined in terms of driving distance. For New Hampshire, the data is obtained from the New Hampshire Economic and Labor Market Information Bureau. For the New England control group states, the data is produced using the code developed by Ozimek and Miles (2011). ${ }^{1}$ The code inputs two pairs of longitude and latitude coordinates and then queries Google Maps for the driving distance. Within New Hampshire, the Ozimek and Miles produced data is extremely similar to the data produced by the New Hampshire Economic and Labor Market Information Bureau. The measures have a raw cross-sectional correlation of 0.99 and the mean difference between the two measures is -1.6 miles, a small fraction of the 85 mile mean distance in the government produced data.

\section{Measures of Land Availability}

Two measures of land availability are used. The first measure is the number of houses per square meter of land from the 2000 Census. The second measure is the percent of land which has been developed. Land is considered developed if it is in use for residential, commercial, industrial or transportation purposes. Land is considered undevelopable, and therefore not included in the denominator of the measure, if it is classified as any of the following: open water, perennial ice or snow, barren, or wetlands. The data was produced by Hilber and Mayer (2009) and is based on

\footnotetext{
${ }^{1}$ Ozimek, A. and D. Miles, "Stata utilities for geocoding and generating travel time and travel distance information" Stata Journal, Volume 11, No. 1, 2011.
} 
the National Land Cover Data 1992. In some cases, the data cannot be mapped uniquely into a single municipality. In these cases, the data are mapped into an area comprised of two or more municipalities and these communities are all assigned the same value.

\section{Land Use Regulation}

Only two forms of land use regulation are available at multiple points in time - growth management and impact fees. These variables are used in the regressions in Table 8 . Impact fees are paid at the time of development and are intended to cover the cost of the public infrastructure associated with development. The impact fee data are available as of 2000 in a dataset on New Hampshire zoning collected by Richard England. The 2008 data come from the New Hampshire Office of Energy and Planning. Impact fees are the only aspect of zoning which can be linked across the two sources / time periods. The growth management data are available for 1999 and 2008. The data come partially from a survey conducted by the author and the remaining data are from the Office of Energy and Planning.

\begin{tabular}{ccc}
\multicolumn{4}{c}{ Appendix Table A1 ${ }^{2}$} & \\
Percent of Municipalities with Land Use Regulation \\
& $1999 / 2000$ & 2008 \\
Growth Management & 0.13 & 0.26 \\
Impact Fees & 0.13 & 0.44
\end{tabular}

\subsection{Heterogeneity in the Investment Response Due to Land Availability and Land Use Regulation}

As discussed in section 6.2 of the text, the geographic heterogeneity in the investment response to the reform is consistent with the hypothesis that housing supply elasticity is relatively higher outside of the suburban ring. Likely explanations for this hypothesized difference in supply elasticity are land availability and regulation. These explanations are explored in Appendix Table A2. Column (1) contains results examining land availability, using an interaction between the grant variable and housing market density - a proxy for land availability. Columns (2) and (3) explore land use regulation. The specification in column (2) includes an interaction between the grant variable and an indicator variable for having a growth management ordinance - a type of land use regulation which sets a binding annual limit on the number of new homes constructed. The interaction

\footnotetext{
${ }^{2}$ Note. The sample is restricted to municipalities with 1200 or more residents in 2000 . The first column contains data from 1999 for growth management and from 2000 for impact fees.
} 
term in column (3) uses an indicator variable for impact fees - payments required of developers to defray the municipal cost of new housing (e.g. new school construction). See the note to Table A2 for further information on these specifications. In all three cases the interaction terms are imprecise and hence uninformative. ${ }^{3}$ Unlike the availability of land, which can be measured relatively accurately, land use regulation is notoriously difficult to quantify (e.g. Nechyba 2001 and Glaeser, Gyourko and Saks 2005). It is therefore possible that the measures used in columns (2) and (3) fail to fully characterize the regulatory environment.

\subsection{The Intensive Margin of Residential Capital Investment}

The measure of the residential capital investment used in this paper - the number of new housing units - captures only the extensive margin of residential investment. A shock to fiscal surplus may also influence the intensive margin of residential investment - the size and quality of both new and existing homes. For instance, with the annual tax cost of renovations and additions falling due to a decline in the property tax rate, homeowners would be expected to increase expenditures on renovations and additions.

Despite the evidence that there is no extensive margin response within the suburban ring, there may very well have been an intensive margin response in this area. The factors which make housing supply inelastic - e.g. zoning, the availability of land, etc.-and which block extensive margin residential investment from responding to a fiscal shock, may not block intensive margin investments such as improvements or additions to existing homes. Intensive margin investment potentially increases the sales value of a property. As a result, the suburban ring "price" response documented in Table 7 may partially reflect a "quantity" response, specifically an intensive margin investment response.

Unfortunately, data on intensive margin residential investment for existing homes are not available for New Hampshire's municipalities and it is therefore not possible to directly estimate the effect of the fiscal reform on this margin. It is possible, however, to use data at a coarser geographic level to gain an understanding of the likely magnitude of the intensive margin response. The Census Bureau's Survey of Residential Alterations and Repairs (SORAR) shows that nearly $\$ 30$ billion (1999 dollars) was spent on residential home improvements in the Northeast census region in 2000. The definition of home improvements is broad and includes all construction activity intended to maintain or improve residential property (e.g. additions, alterations, repairs, etc.). The 2000 decennial census counts around 22.6 million residential housing units in the Northeast region. Thus,

\footnotetext{
${ }^{3}$ Specifications using other measures of land availability, such as the percent of land developed, and other measures of land use regulation, such as elements of municipal zoning codes, also produce uninformative results (unreported).
} 
average intensive margin residential investment equaled roughly $\$ 1,325$ in the region in 2000 .

Assume that the fiscal shock increased intensive margin residential investment by 16 percent equal to the extensive margin investment response outside of the suburban ring (see section 3.4.3). Under this assumption, the fiscal shock increased intensive margin investment by around $\$ 212$ per year in the suburban ring $\left(\$ 1,325^{*} 0.16\right)$. Over the four post-shock years used in the sample, this would be expected to increase the value of a home by an average of $\$ 530 .{ }^{4}$ Within the suburban ring, the fiscal shock increased home values by $5 \%$ (see section 3.4.4). As the mean sales price of existing homes in the suburban ring over the four post-shock years is around $\$ 237,000$, the typical suburban ring home experienced an increase in value of roughly $\$ 11,850(\$ 237,000 * 0.05)$. Thus, these calculations suggest that the intensive margin investment response accounts for roughly $4 \frac{1}{2}$ percent $(\$ 530 / \$ 11,850)$ of the overall suburban ring price response documented in Table 7 .

The intensive margin response calculation is extremely rough and subject to any number of possible critiques. Nonetheless, the calculation suggests that, under plausible assumptions, the intensive margin response is unlikely to account for a significant portion of the suburban ring price response. For instance, even if the intensive margin response was assumed to be double the magnitude of the extensive margin response (32 percent instead of 16 percent), the intensive margin response would still account for only 9 percent of the price response documented in Table 7.

\footnotetext{
${ }^{4}$ The first year increase in value is $\$ 212$; the second year cumulative increase in value is $\$ 424$; the third year cumulative increase in value is $\$ 636$; the fourth year cumulative increase in value is $\$ 848$. The mean of these incremental increases in value is $\$ 530$.
} 
Figure A1: Education Funding by Level of Government

Panel A: Local Share of Education Funding

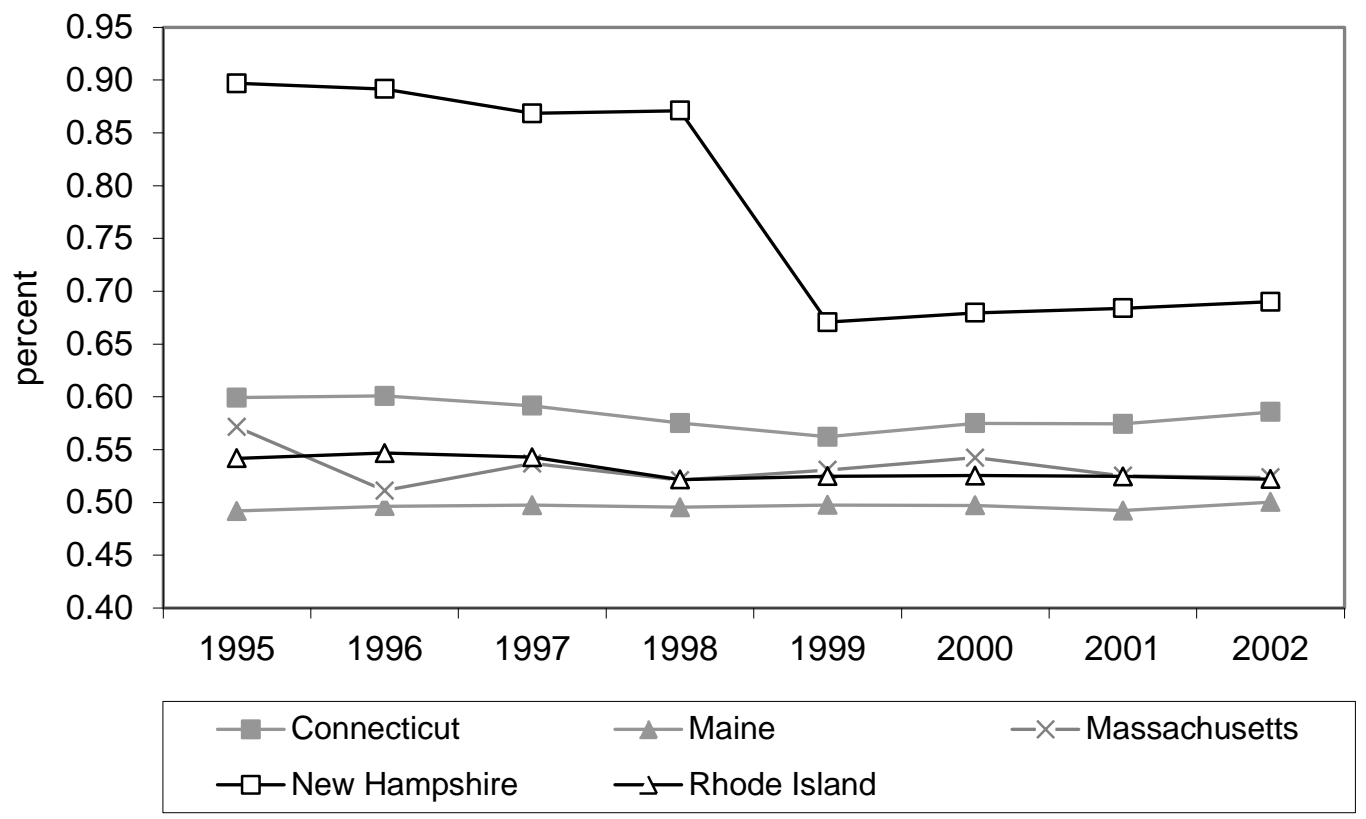

Panel B: State Share of Education Funding

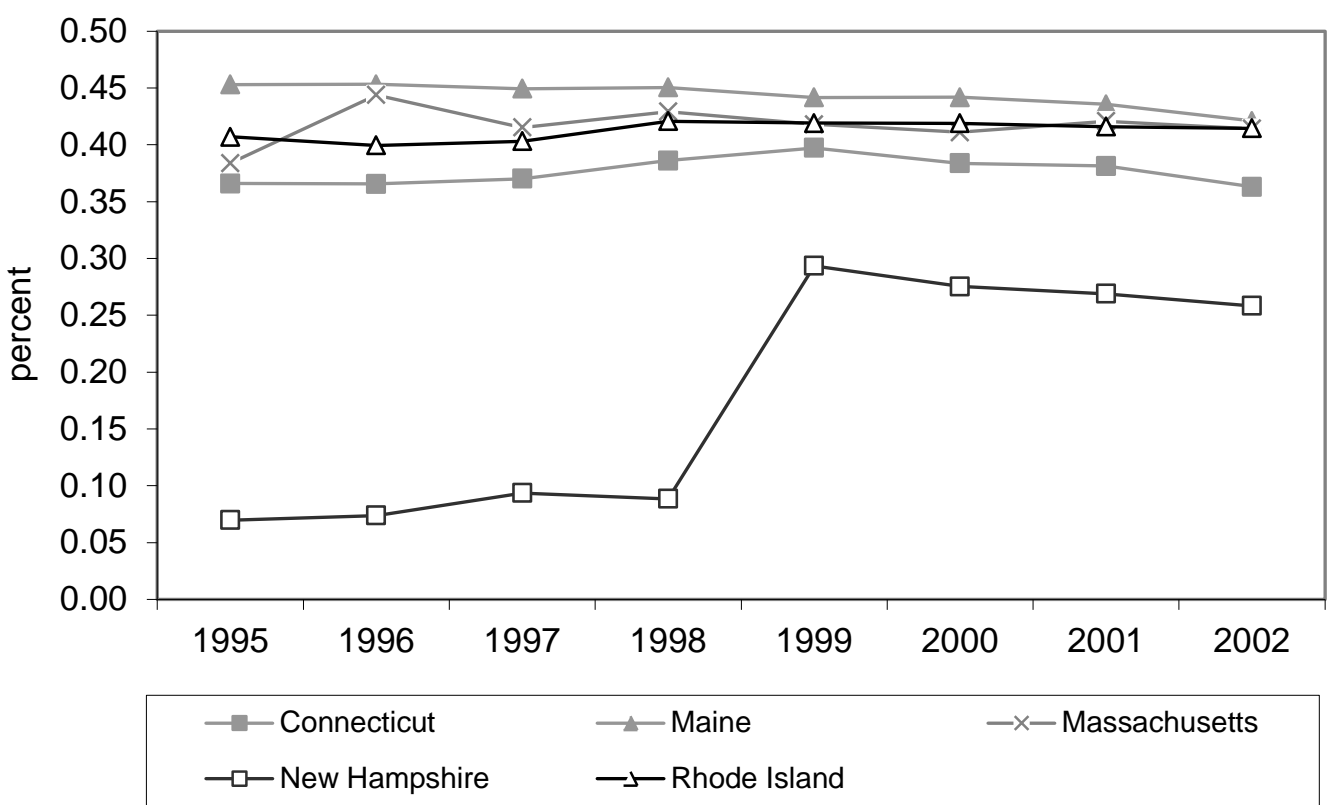

Note. Data from Census Bureau School Finance data, New Hampshire Department of Education and New Hampshire Department of Revenue Administration. 
Figure A2: Monocentric Map of New England

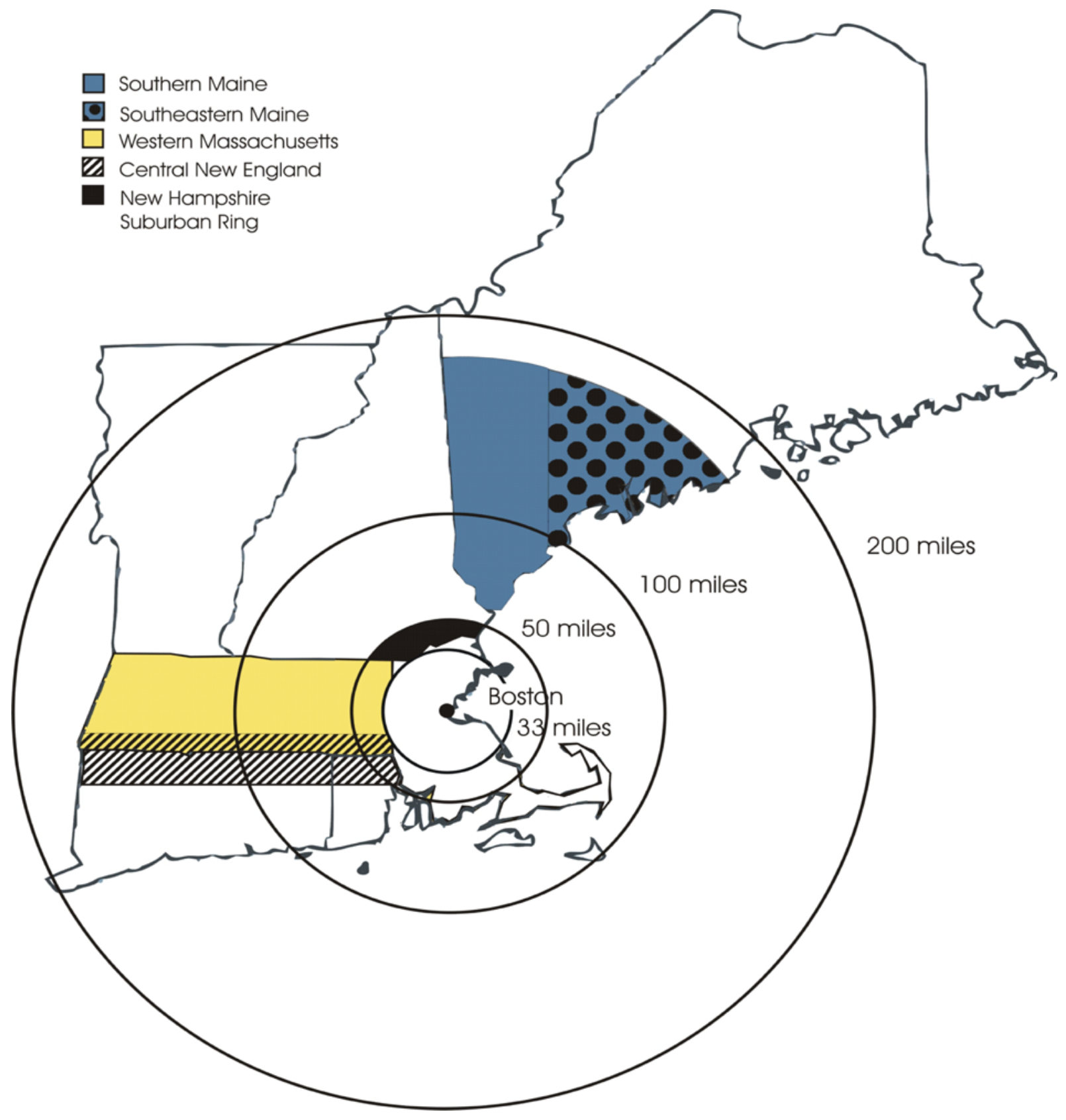


Table A2

Effect of Change in Fiscal Surplus on Residential Investment: Land Availability and Land Regulation

(Grant / Tax Revenue) * (year >= 2000)

Land

Availability

Land Use Regulation

\begin{tabular}{|c|c|c|}
\hline$(1)$ & $(2)$ & $(3)$ \\
\hline \multicolumn{3}{|c|}{ (Building Permits / Homes) *100 } \\
\hline 1.41 & 1.17 & 1.09 \\
\hline$(1.57)$ & $(0.56)$ & $(0.53)$ \\
\hline
\end{tabular}

(Grant / Tax Revenue) * (Log of Housing Density in 1996) * (year >= 2000)

$-0.12$

$(0.49)$

(Grant / Tax Revenue) * (Growth Management in 1999) * (year >= 2000)

(Grant / Tax Revenue) * (Impact Fees in 1999)* (year >= 2000)

Number of Observations

Note. Grant / Tax Revenue refers to the ratio of the net grant in 1999 to property tax revenue in 1998. The unit of observation is municipality-year.

The dependent variable is the ratio of single-family building permits to the number of single-family homes in 1996 multiplied by 100 . Standard errors clustered by municipality are in parentheses. The date range of the data is 1996 to 2003, with 1999 omitted from the sample (see text). The sample is restricted to the set of municipalities with greater than 1200 residents in 2000 with at least six years of non-missing building permit data. All

columns include municipal and year fixed-effects. All columns include main interaction effects: For example, column (1) includes in the specification (log of housing density) * (year $>=2000)$. The coefficient estimates for these main effects are not displayed. Full set of results available from author upon request. 